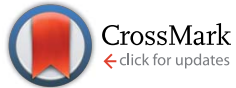

Cite this: RSC Adv., 2017, 7, 720

Received 11th October 2016 Accepted 20th November 2016

DOI: 10.1039/c6ra25070j

www.rsc.org/advances

\section{Enhanced flame-retardant effect of a montmorillonite/phosphaphenanthrene compound in an epoxy thermoset}

\author{
Shuo Tang, ${ }^{\text {ab }}$ Volker Wachtendorf, ${ }^{c}$ Patrick Klack, ${ }^{c}$ Lijun Qian, ${ }^{* b}$ Yuping Dong ${ }^{a}$ \\ and Bernhard Schartel ${ }^{\star c}$
}

A phosphaphenanthrene and triazinetrione group containing flame retardant (TAD) is combined with organically modified montmorillonite (OMMT) in epoxy resin thermosets (EP) to improve the performance of the flame-retardant system. When only $1 \mathrm{wt} \%$ OMMT/4 wt\% TAD is introduced into the EP, the limited oxygen index (LOI) rises from $26 \%$ to $36.9 \%$ and a $\mathrm{V}-0$ rating is achieved in a UL 94 test. The decomposition and pyrolysis products in the gas phase and condensed phase were characterized using thermogravimetry-Fourier transform infrared spectroscopy (TG-FTIR). The influence on the decomposition of EP, such as the increase in char yield, is limited with the incorporation of OMMT; a large amount of the phosphorus is released into the gas phase. The flame-retardant effect evaluation based on cone calorimeter data testified that OMMT improves the protective-barrier effect of the fire residue of OMMT/TAD/EP on the macroscopic scale, while TAD mainly causes flame inhibition. The fire residues showed a corresponding macroscopic appearance (digital photo) and microstructure (scanning electron microscope [SEM] results). The protective barrier effect of OMMT and the flame-inhibition effect of TAD combined to exert a superior flame-retardant effect, resulting in sufficient flame-retardant performance of OMMT/TAD/EP.

\section{Introduction}

Epoxy resins have been used widely in many fields due to their excellent properties, such as outstanding electrical insulation, corrosion resistance, and adhesive properties. ${ }^{1-4}$ Therefore, they are widely used as adhesives in printed circuit boards and packaging materials, and applied in other fields including surface coatings and painting materials. ${ }^{5-8}$ Unfortunately, the flammability of epoxy resins restricts their application in the field of flame-retarded materials. ${ }^{\mathbf{9}-11}$ To expand their application in this field, many studies have been performed to improve the flame retardancy of epoxy resins via the addition of various flame retardants. ${ }^{\mathbf{1 2 - 1 4}}$

9,10-Dihydro-9-oxa-10-phosphaphenanthrene-10-oxide (DOPO) and its derivatives are one of the most commonly used flame retardants for epoxy resins due to their dramatic flameretardant effect. ${ }^{15-18}$ They exert a flame-retardant quenching effect through the release of free $\mathrm{PO}_{2}{ }^{\circ}$ and $\mathrm{PO}^{\circ}$ radicals and disturb the combustion chain reaction in the gas phase, as well as interacting with the decomposing polymer and inducing

${ }^{a}$ School of Materials, Beijing Institute of Technology, Beijing 100081, PR China ${ }^{b}$ School of Materials Science and Mechanical Engineering, Beijing Technology and Business University, Beijing 100048, PR China.E-mail: qianlj@th.btbu.edu.cn

${ }^{c}$ Bundesanstalt für Materialforschung und prüfung (BAM), Unter den Eichen 87, 12205 Berlin, Germany. E-mail: bernhard.schartel@bam.de charring in the condensed phase. ${ }^{19-21}$ To further improve the flame retardant properties of epoxy resins, many kinds of DOPO derivatives containing different flame retardant groups such as triazine, ${ }^{22}$ pentaerythritol, ${ }^{23}$ diphosphonate, ${ }^{24}$ silsesquioxane ${ }^{25}$ have been synthesized and applied to flame-retardant polymeric materials.

Inorganic flame retardants have frequently been applied to flame-retardant epoxy resins due to their low cost, low toxicity and high thermal stability. ${ }^{26-28}$ Among them, organically modified montmorillonite (OMMT) is often chosen to improve the flame resistance and thermal properties of epoxy resins and polyamides. $^{29,30}$ As OMMT can work as a protective barrier to flame, suppress smoke ${ }^{31}$ and act as a heat storage medium, ${ }^{32}$ it is often used as an adjuvant to improve flame-retardant systems. ${ }^{33}$

In this work, a DOPO derivative with phosphaphenanthrene and triazinetrione groups, TAD, was applied in epoxy resins, and its molecular structure was shown in Fig. 1. TAD showed a good flame-retardant effect in the gas phase. To improve the flame-retardant efficiency of TAD, OMMT was incorporated into epoxy resin thermosets (EP) based on diglycidyl ether of bisphenol-A (DGEBA) and 4,4'-diamino-diphenyl methane (DDM), flame-retarded with TAD. OMMT was proposed to be an effective inorganic adjuvant inducing protective barrier effects. The flame retardancy of the OMMT/TAD system in EP was explored and the flame-retardant modes of action were discussed. 


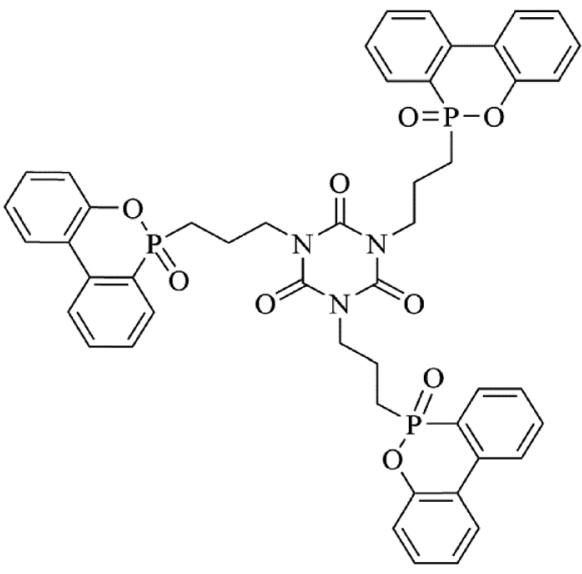

Fig. 1 Molecular structure of TAD.

\section{Experimental}

\subsection{Materials}

The epoxy resin, diglycidyl ether of bisphenol-A (DGEBA), was purchased from Blue Star New Chemical Material Co. Ltd., China. TAD was prepared in our own laboratory, and the details are presented in our previous article. ${ }^{34}$ OMMT (DK4 style) was provided by Zhejiang Fenghong New Material Co. Ltd., China. 4,4'-Diamino-diphenyl methane (DDM) was purchased from Sinopharm Chemical Reagent Co. Ltd., China.

\subsection{Preparation of epoxy thermosets}

DGEBA, TAD and OMMT were heated to $135^{\circ} \mathrm{C}$ and stirred for $0.5 \mathrm{~h}$ at $100{ }^{\circ} \mathrm{C}$. DDM was then added into the mixture at $120^{\circ} \mathrm{C}$ and blended thoroughly. After the mixture was degassed for $3 \mathrm{~min}$ at $120{ }^{\circ} \mathrm{C}$, it was poured into preheated molds and cured for $2 \mathrm{~h}$ at $120^{\circ} \mathrm{C}$ and then for $4 \mathrm{~h}$ at $170{ }^{\circ} \mathrm{C}$ to obtain $4 \% \mathrm{TAD} / 1 \%$ OMMT/EP. EP was prepared in the same manner, but without the addition of the flame retardant TAD. EP with OMMT and TAD were also prepared and named 1\% OMMT/EP and $4 \% \mathrm{TAD} /$ EP, respectively. The content of DGEBA, DDM, TAD and OMMT in each epoxy resin thermoset is listed in Table 1.

\subsection{Characterization}

Fourier transform-infrared spectroscopy. FT-IR spectra were obtained using a Nicolet iN10MX-type spectrometer. The powdered samples were thoroughly mixed with $\mathrm{KBr}$ and then pressed into pellets.

Table 1 Formulation of the EP thermosets

\begin{tabular}{|c|c|c|c|c|c|c|}
\hline \multirow[b]{2}{*}{ Samples } & \multirow[b]{2}{*}{ DGEBA/g } & \multirow[b]{2}{*}{$\mathrm{DDM} / \mathrm{g}$} & \multicolumn{2}{|c|}{ OMMT } & \multicolumn{2}{|l|}{ TAD } \\
\hline & & & $g$ & wt\% & $\mathrm{g}$ & wt $\%$ \\
\hline EP & 100.0 & 25.3 & - & - & - & - \\
\hline 1\% OMMT/EP & 100.0 & 25.3 & 1.27 & 1 & - & - \\
\hline $4 \% \mathrm{TAD} / \mathrm{EP}$ & 100.0 & 25.3 & - & - & 5.22 & 4 \\
\hline $4 \%$ TAD/1\% OMMT/EP & 100.0 & 25.3 & 1.32 & 1 & 5.27 & 4 \\
\hline $5 \% \mathrm{TAD} / \mathrm{EP}$ & 100.0 & 25.3 & - & - & 6.59 & 5 \\
\hline
\end{tabular}

Limited oxygen index (LOI) measurement. The limited oxygen index (LOI) was measured using an FTT (Fire Testing Technology, UK) Dynisco LOI instrument according to ASTM D2863-97 (sample dimensions: $130 \mathrm{~mm} \times 6.5 \mathrm{~mm} \times 3.2 \mathrm{~mm}$ ).

Vertical burning test. The vertical burning test for the UL 94 combustion level was performed using an FTT0082 instrument according to ASTM D 3801 (sample dimensions: $125 \mathrm{~mm} \times 12.7$ $\mathrm{mm} \times 3.2 \mathrm{~mm})$.

Cone calorimeter test. Fire behavior was characterized using a FTT cone calorimeter based on ISO 5660 at an external heat flux of $50 \mathrm{~kW} \mathrm{~m}{ }^{-2}$. The samples were $100 \mathrm{~mm} \times 100 \mathrm{~mm} \times 4$ $\mathrm{mm}$ in size. The reported parameters are the average of three measurements.

Scanning electron microscope. The micromorphology images of the fire residues after cone calorimeter test were obtained using a FP 2032/14 Quanta 250 FEG scanning electron microscope at high vacuum conditions with a voltage of $20 \mathrm{kV}$.

Element analysis. The chemical contents of fire residues from cone calorimeter test were investigated with a Perkin Elmer PHI 5300 ESCA X-ray photoelectron spectrometer (XPS). The tested specimens were taken from the sufficiently mixed and ground residues.

Thermogravimetry-Fourier transform-infrared spectroscopy (TGA-FTIR). Thermogravimetric analysis (TGA) was performed using the TG 209 F1 Iris (Netzsch Instruments, Selb, Germany) coupled with a Fourier transform infrared spectrometer (FTIR, Tensor 27, Bruker Optics, Ettlingen, Germany). The transfer line and the gas cell were heated up to $270{ }^{\circ} \mathrm{C}$ to analyze the evolved gases during decomposition. ${ }^{35}$ The materials were cut into small pieces and $10 \mathrm{mg}$ were measured under nitrogen flow $(30 \mathrm{~mL}$ $\min ^{-1}$ ) at a heating rate of $10 \mathrm{~K} \mathrm{~min}^{-1}$. The attribution of peaks to functional groups was done using gas-phase reference spectra. The ones used for the interpretation were from the literature on bisphenol A (HR Nicolet Vapor Phase), diphenyl methane (HR Nicolet Vapor Phase) and aniline (HR Nicolet Vapor Phase). Our own measurements were used for the gas-phase spectrum of 9,10dihydro-9-oxa-10-phosphaphenanthrene-10-oxide (DOPO) and flame retardants containing DOPO. ${ }^{\mathbf{1 , 2 1}}$

Fourier transform-infrared spectroscopy using a Linkam cell. The changes in the condensed phase were investigated using a Vertex70 FTIR spectrometer (Bruker Optics) during pyrolysis. The spectrometer was equipped with an FTIR600 Linkam hot-stage cell (Linkam Scientific Instruments Ltd., Chilworth, UK). Eight mg of the materials, which were milled under liquid nitrogen using a CryoMill (Retsch, Germany), were mixed with $200 \mathrm{mg}$ dried $\mathrm{KBr}$. The mixture was ground with an agate mortar and pressed into a disc with a hydraulic press at $7 \mathrm{t}$. The discs were placed in the Linkam hot stage and heated from $30{ }^{\circ} \mathrm{C}$ to $600{ }^{\circ} \mathrm{C}$ at a heating rate of $10 \mathrm{~K} \mathrm{~min}^{-1}$ under

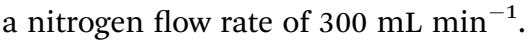

\section{Results and discussion}

\subsection{LOI and UL 94 tests}

The flame-retardant properties of the epoxy composites were determined using LOI and UL 94 vertical burning tests. The results are shown in Table 2. The EP sample achieved a LOI 
Table $2 \mathrm{LOI}$ and UL 94 testing results of EP composites

\begin{tabular}{lllllll}
\hline & \multicolumn{5}{c}{ UL 94} \\
\cline { 3 - 6 } Samples & LOI/\% & $\bar{t}_{1} / \mathrm{s}$ & $\bar{t}_{2} / \mathrm{s}$ & Dripping & Rating \\
\hline EP & $26.0 \pm 0.2$ & Infinite & - & No & NR \\
1\% OMMT/EP & $29.3 \pm 0.2$ & 110.0 & - & No & NR \\
$4 \%$ TAD/EP & $33.6 \pm 0.3$ & 10.3 & 4.3 & No & V-1 \\
$4 \%$ TAD/1\% OMMT/EP & $36.9 \pm 0.2$ & 5.2 & 3.1 & No & V-0 \\
$5 \%$ TAD/EP & $34.6 \pm 0.3$ & 7.4 & 3.5 & No & V-1 \\
& & & & & \\
\hline
\end{tabular}

value of $26.0 \%$, but no rating (NR) in the vertical UL 94 test. While the LOI value of the 1\% OMMT/EP sample increased to $29.3 \%$, the vertical UL 94 rating still remained NR. OMMT itself improved the LOI of EP, but has almost no positive effect on UL 94 test. When $4 \%$ TAD was incorporated into EP, the LOI value rose by $7.3 \%$ over EP, reaching $33.6 \%$, and the UL 94 test achieved a $\mathrm{V}-1$ rating. Further, when OMMT and TAD were added to EP with a mass ratio of $4: 1$, the LOI value of $4 \% \mathrm{TAD} / 1 \%$ OMMT/EP rose to $36.9 \%$, a further $3.3 \%$ more than $4 \%$ TAD/EP, and the sample achieved a V-0 rating in the UL 94 test. OMMT evidently improved the LOI value of the $4 \%$ TAD/EP system, indicating an additive effect between the two additives in the LOI test. In UL 94 testing, OMMT helped 4\% TAD/1\% OMMT/EP to achieve a higher rating than the $4 \% \mathrm{TAD} / \mathrm{EP}$ sample. As the desired V-0 rating is achieved, OMMT proved extremely effective at increasing the flame retardancy of the TAD/EP sample when OMMT and TAD were incorporated into the material in an appropriate ratio. The flame-retardancy modes of action and how OMMT and TAD worked together will be discussed in the following sections.

\subsection{Pyrolysis: mass, evolved gas and residue analysis}

The pyrolysis of all materials was investigated with TGA under nitrogen coupled with evolved gas analysis. The TGA curves (mass versus temperature) are shown in Fig. 2a, the FTIR spectra in Fig. 2b, and the typical TGA results are listed in Table 3. EP, 1\% OMMT/EP, 4\% TAD/EP, and 4\% TAD/1\% OMMT/EP decomposed in one pronounced decomposition step. The mass loss of EP was $82.5 \mathrm{wt} \%$. The beginning of decomposition ( $T_{5 \%}$, temperature at $5 \mathrm{wt} \%$ mass loss) and the decomposition temperature at the maximum mass loss rate $\left(380{ }^{\circ} \mathrm{C}\right)$ hardly changed when OMMT or TAD was added (Table 3 ). The residues increased only slightly when TAD and TAD/OMMT were added, by $1-2 \mathrm{wt} \%$, an effect hardly greater than the uncertainty of admissible error. Even though the amounts of flame retardants were also very small ( $4 \mathrm{wt} \%$ TAD and $1 \mathrm{wt} \% \mathrm{OMMT}$ ), TAD and OMMT exerted only a limited effect in the condensed phase. A relevant reduction in fire risk due to enhanced charring of fuel was ruled out. A limited action in the condensed phase of DGEBA-based EP has been reported before for similar flame retardants based on DOPO-isocyanurate. ${ }^{1,21}$ The observed improvement in LOI and UL 94 is not caused by any molecular mechanisms resulting in increased charring.

The limited impact on the decomposition of EP was also observed in evolved gas analysis using TGA-FTIR. Fig. 3 shows a)

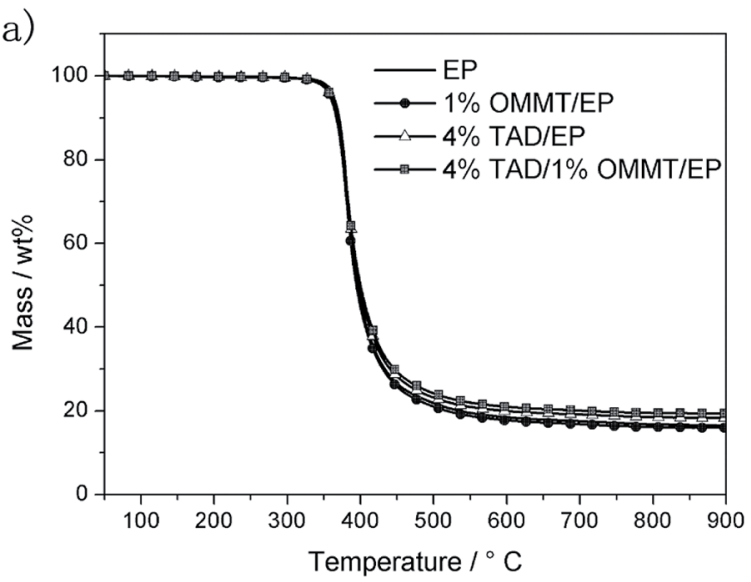

b)

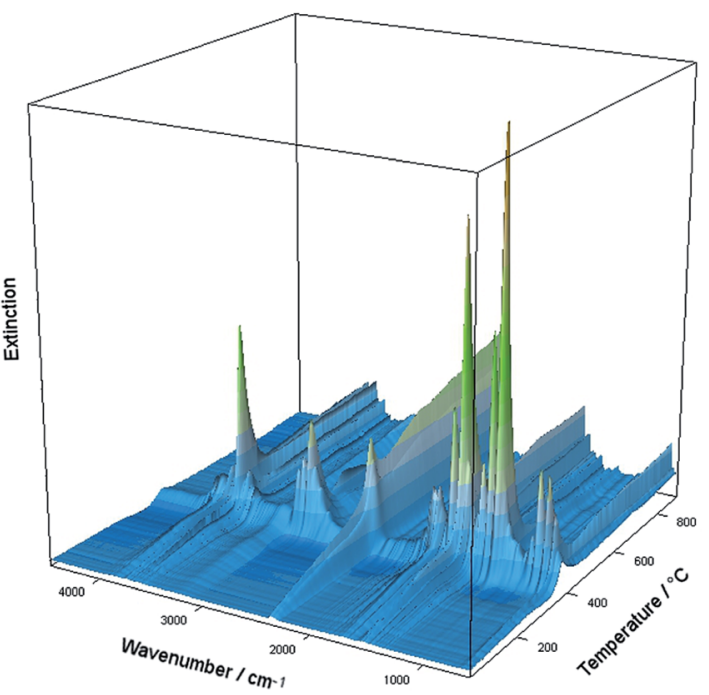

Fig. 2 TGA-FTIR under nitrogen: (a) mass of EP, 1\% OMMT/EP, 4\% $\mathrm{TAD} / \mathrm{EP}$, and $4 \% \mathrm{TAD} / 1 \% \mathrm{OMMT/EP}$ and (b) 3D plot of the IR gas spectra of EP versus the temperature of the TGA.

Table 3 Characteristic results of TGA under nitrogen for EP, 1\% OMMT/EP, 4\% TAD/EP, and 4\% TAD/1\% OMMT/EP

\begin{tabular}{lccc}
\hline & & & $\begin{array}{l}\text { Residue at } \\
800{ }^{\circ} \mathrm{C} / \mathrm{wt} \%\end{array}$ \\
\hline EP & $360 \pm 3$ & $380 \pm 1$ & $17.5 \pm 1.0$ \\
1\% OMMT/EP & $360 \pm 3$ & $380 \pm 1$ & $16.4 \pm 1.0$ \\
$4 \% \mathrm{TAD} / \mathrm{EP}$ & $360 \pm 1$ & $383 \pm 2$ & $18.5 \pm 1.0$ \\
$4 \% \mathrm{TAD} / \mathrm{C} \% \mathrm{OMMT} / \mathrm{EP}$ & $359 \pm 1$ & $382 \pm 1$ & $19.5 \pm 1.0$
\end{tabular}

the FTIR gas spectra for EP, 1\% OMMT/EP, $4 \%$ TAD/EP, and $4 \%$ $\mathrm{TAD} / 1 \%$ OMMT/EP at the decomposition temperature $\left(T_{\max }=\right.$ $380-383^{\circ} \mathrm{C}$ ) in TGA. All spectra were dominated by the spectrum of EP, showing the release of $\mathrm{H}_{2} \mathrm{O}\left(4000 \mathrm{~cm}^{-1}\right.$ to $3400 \mathrm{~cm}^{-1}$ and $2200 \mathrm{~cm}^{-1}$ to $\left.1700 \mathrm{~cm}^{-1}\right)$, free $\mathrm{OH}\left(3649 \mathrm{~cm}^{-1}\right), \mathrm{C}_{\text {aromatic }}-\mathrm{H}$ (3035 $\left.\mathrm{cm}^{-1}, 831 \mathrm{~cm}^{-1}, 746 \mathrm{~cm}^{-1}\right), \mathrm{CH}_{4}\left(3016 \mathrm{~cm}^{-1}\right), \mathrm{C}_{\text {aromatic }^{-}}$ $\mathrm{C}_{\text {aromatic }}$ stretch $\left(1606 \mathrm{~cm}^{-1}, 1508 \mathrm{~cm}^{-1}\right), \mathrm{C}_{\text {aliphatic }}-\mathrm{H}(2974$ $\left.\mathrm{cm}^{-1}, 2935 \mathrm{~cm}^{-1}, 2881 \mathrm{~cm}^{-1}, 1460 \mathrm{~cm}^{-1}\right), \mathrm{CO}_{2}\left(2359 \mathrm{~cm}^{-1}\right)$, $\mathrm{CHO}\left(2814 \mathrm{~cm}^{-1}\right)$, lactones $\left(1797 \mathrm{~cm}^{-1}, 1772 \mathrm{~cm}^{-1}\right), \mathrm{C}=\mathrm{O}(1716$ $\left.\mathrm{cm}^{-1}\right), \mathrm{C}-\mathrm{H}$ of bisphenol A $\left(1331 \mathrm{~cm}^{-1}, 1176 \mathrm{~cm}^{-1}\right), \mathrm{RC}=\mathrm{CH}_{2}$ 
a)

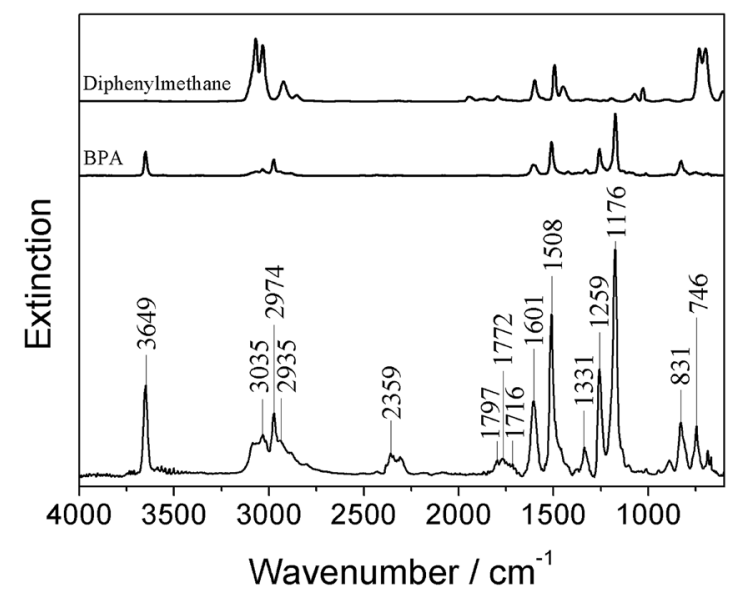

b)

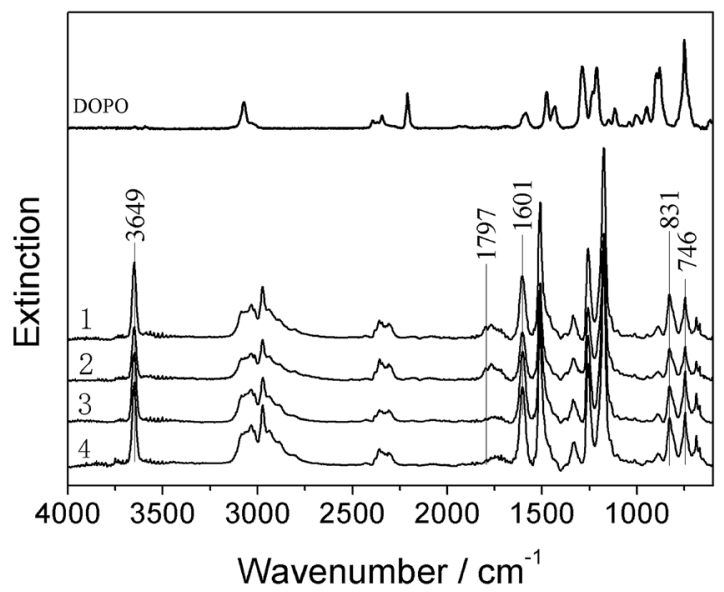

Fig. 3 Pyrolysis (TGA-FTIR under nitrogen): FTIR gas spectra of (a) EP and reference gas phase spectra for diphenylmethane, and bisphenol A (BPA); (b) 1: EP, 2: 1\% OMMT/EP, 3: 4\% TAD/EP, and 4: 4\% TAD/1\% OMMT/EP and reference gas phase spectra for DOPO.

(887 $\left.\mathrm{cm}^{-1}\right)$, C-O and $\mathrm{C}-\mathrm{H}$ of bisphenol A $\left(1259 \mathrm{~cm}^{-1}\right)$. Most peaks of the spectra are associated with bisphenol- $\mathrm{A},{ }^{36}$ which is part of the DGEBA resin component. ${ }^{1,10}$ Bisphenol A actually dominates the spectrum of EP, as it does for all of the other investigated materials. An additional contribution from diphenyl methane was concluded, which is part of the DDM hardener used. There may also be a contribution of aniline as a possible product from DDM decomposition, instead of or in addition to diphenyl methane.

Adding OMMT or TAD did not generate any new peaks or shoulders of noticeable height. However differences occurred in the peak ratios. Hence, the spectra are considered qualitatively identical with respect to the same main decomposition products; quantitatively there are differences, indicating a variation in the concentration of the released decomposition products. Furthermore, any increase in peak height may be due to an additional peak overlapping with a peak originating from EP. The peak around $750 \mathrm{~cm}^{-1}$, and the peak height sequence $4 \%$ $\mathrm{TAD} / 1 \% \mathrm{OMMT} / \mathrm{EP}=4 \% \mathrm{TAD} / \mathrm{EP}>\mathrm{EP}=1 \% \mathrm{OMMT} / \mathrm{EP}$, suggests that there is a specific contribution from the phosphorous-containing DOPO group of TAD. A comparison with the gas-phase spectrum of DOPO at $750 \mathrm{~cm}^{-1}$ can confirm this opinion. The incorporation of OMMT did not affect the peak intensity at $750 \mathrm{~cm}^{-1}$, in contrast to that of the sample with just TAD. In the carbonyl region between about $1700 \mathrm{~cm}^{-1}$ and $1800 \mathrm{~cm}^{-1}$, the peaks at $1772 \mathrm{~cm}^{-1}$ and $1797 \mathrm{~cm}^{-1}$ are attributed to lactones. OMMT/TAD or TAD equally inhibited the release of lactones. Other components are the $\mathrm{CO}_{2}$ peak at 2359 $\mathrm{cm}^{-1}$, and water showing vibrations in the regions of $4000 \mathrm{~cm}^{-1}$ to $3400 \mathrm{~cm}^{-1}$ and $2200 \mathrm{~cm}^{-1}$ to $1700 \mathrm{~cm}^{-1} \cdot \mathrm{CO}_{2}$ release decreases in the sequence: $1 \% \mathrm{OMMT} / \mathrm{EP}>\mathrm{EP}>4 \% \mathrm{TAD} / 1 \%$ $\mathrm{MMT} / \mathrm{EP}>4 \% \mathrm{TAD} / \mathrm{EP} . \mathrm{CO}_{2}$ release was higher for the nonphosphorous mixtures. Thus, the analysis of the evolved gases testifies to the release of phosphorus into the gas phase and only some minor additional changes in the amount of products. OMMT in 1\% OMMT/EP and 4\% TAD/1\% OMMT/EP did not affect the evolved gases at all. The results for the evolved gases are in agreement with the negligible changes discussed for the decomposition temperatures and char yield. The release of phosphorus during the main decomposition step indicates flame inhibition for $4 \% \mathrm{TAD} / \mathrm{EP}$ and $4 \% \mathrm{TAD} / 1 \% \mathrm{OMMT} / \mathrm{EP}$, whereas for OMMT no molecular mechanisms occur during pyrolysis, explaining the flame retardancy.

Fig. $4 \mathrm{a}$ and $\mathrm{b}$ show the FTIR spectra of $\mathrm{EP}$ and $4 \% \mathrm{TAD} / \mathrm{EP}$ at room temperature, around $450{ }^{\circ} \mathrm{C}$ and $600{ }^{\circ} \mathrm{C}$. In Fig. $4 \mathrm{c}$ the spectra of the four materials investigated during pyrolysis are compared. All spectra are dominated by the EP spectrum. There is no obvious difference between EP and $1 \%$ OMMT/EP, or between $4 \% \mathrm{TAD} / \mathrm{EP}$ and $4 \% \mathrm{TAD} / 1 \%$ OMMT/EP. OMMT had no chemical effect in $4 \% \mathrm{TAD} / 1 \%$ OMMT/EP during combustion. $4 \% \mathrm{TAD} / \mathrm{EP}$ and $4 \% \mathrm{TAD} / 1 \%$ OMMT/EP showed an additional peak at $1692 \mathrm{~cm}^{-1}$. This peak is attributed to $\mathrm{N}-\mathrm{C}=\mathrm{O}$ and thus to the isocyanurate ring of TAD. Further, the peaks at $914 \mathrm{~cm}^{-1}$ and $755 \mathrm{~cm}^{-1}$ became stronger when TAD is added. The peak at $755 \mathrm{~cm}^{-1}$ is attributed to $\mathrm{H}-\mathrm{C}_{\text {aromatic }}$ for an ortho-substituted phenyl, the one at $914 \mathrm{~cm}^{-1}$ to $\mathrm{P}-\mathrm{O}-\mathrm{C}_{\text {aromatic }}$.

During heating, the intensity of all bands decreases. Several bands vanish, such as the $1692 \mathrm{~cm}^{-1}$ for $4 \% \mathrm{TAD} / \mathrm{EP}$ and $4 \%$ $\mathrm{TAD} / 1 \%$ OMMT/EP, showing that the isocyanurate ring decomposed. ${ }^{1,21}$ Hardly any further significant differences were observed when the different materials were compared (Fig. 4c); in particular, $4 \% \mathrm{TAD} / 1 \%$ OMMT/EP showed IR spectra and decomposition identical to those of $4 \% \mathrm{TAD} / \mathrm{EP}$. The results for the condensed phase indicate that the decomposition of the EP and the flame retardants occurred without significant interactions. Like the TGA and TGA-FTIR results, the investigation of the decomposition in the condensed phase did not deliver significant interactions with respect to the molecular decomposition. The pyrolysis products in the gas and condensed phases are the same for $4 \% \mathrm{TAD} / \mathrm{EP}$ thermosets with or without OMMT. The phosphorus is mainly released; only minor charring activity is concluded.

\subsection{Cone calorimeter test}

To explore the fire behavior of the materials investigated, particularly the flame retardant behavior of OMMT/TAD, cone 
a)

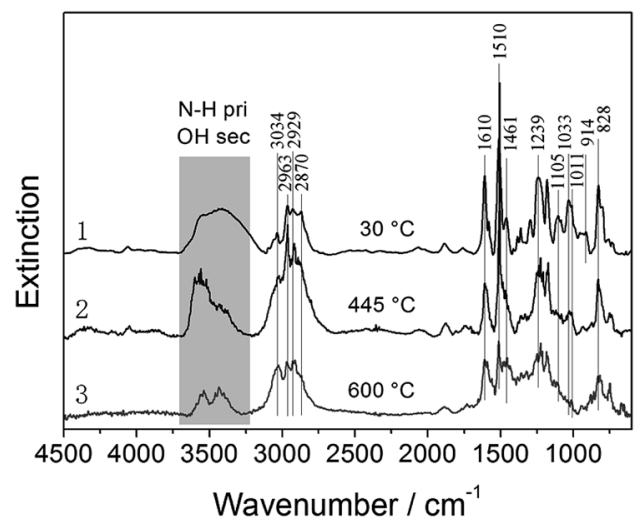

b)

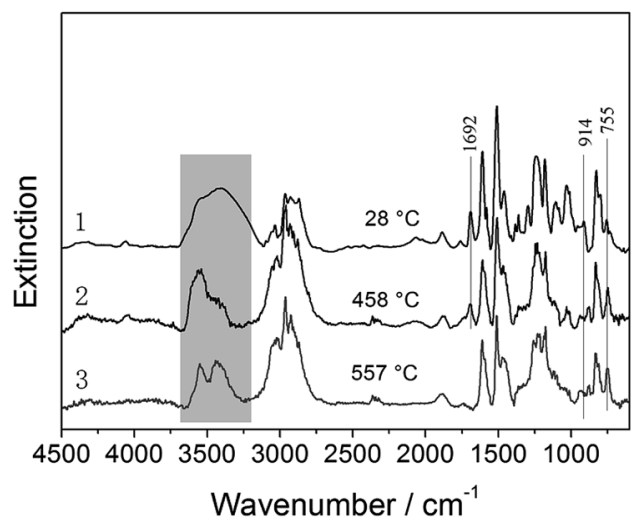

c)

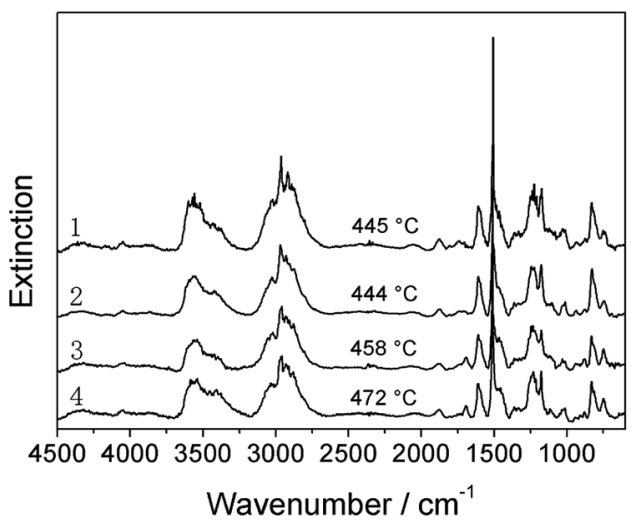

Fig. 4 FTIR spectra of residues (condensed phase): (a) EP, (b) 4\% TAD/ EP, and (c) comparing 1: EP, 2: 1\% OMMT/EP, 3: 4\% TAD/EP and 4: 4\% TAD/1\% OMMT/EP during decomposition.

calorimeter tests were conducted. The curves of the heat release rate (HRR) are shown in Fig. 5, and partial characteristic parameters, such as peak of heat release rate (pk-HRR), average effective heat of combustion (av-EHC), total heat release (THR), average $\mathrm{CO}$ yield (av-COY), average $\mathrm{CO}_{2}$ yield $\left(\mathrm{av}-\mathrm{CO}_{2} \mathrm{Y}\right)$, total smoke release (TSR) and total mass loss (TML) are summarized in Table 4.

Somehow OMMT enhanced the burning of $1 \%$ OMMT/EP. As shown in Fig. 5 and Table 4, the pk-HRR and the total mass loss (TML) of $1 \%$ OMMT/EP were similar to those of EP, but the time

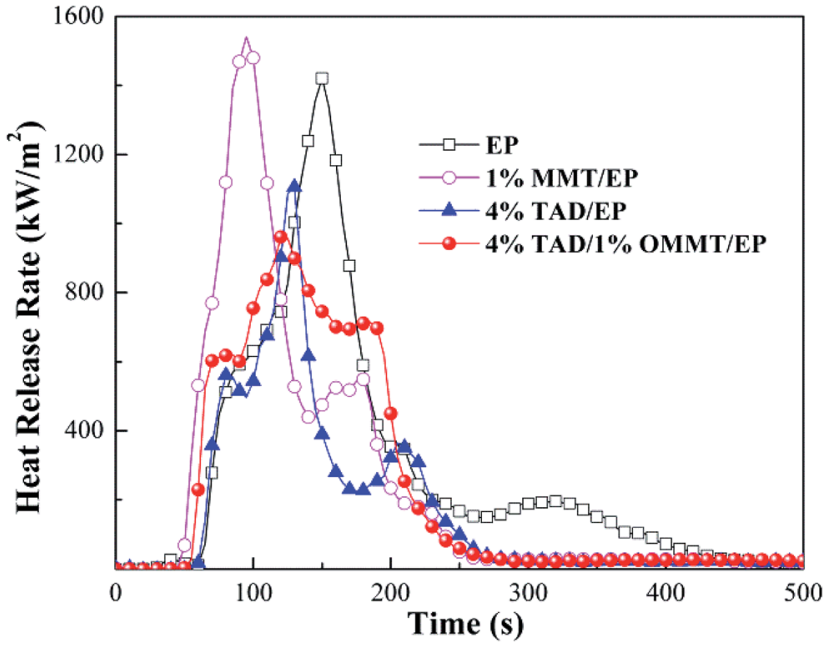

Fig. 5 HRR curves of flame-retardant epoxy composites.

to reach the pk-HRR and TTI obviously decreased compared to EP. Therefore, OMMT essentially contributes to the fire behavior of EP, and caused the earlier pyrolysis of EP matrix during combustion. This is possibly because OMMT formed a "wick effect" during combustion or changed the viscosity of the pyrolyzing melt, reducing heat transfer from the igniting surface layer into the specimen through convection. In contrast, TAD showed obvious flame retardancy through flame inhibition. As a high-performance flame retardant with two typical flame-retarding groups, $4 \%$ TAD in EP remarkably reduced pkHRR, THR, av-EHC, and TML. Fire behavior was efficiently inhibited by the addition of TAD. Assuming that the flamepromotion effect of OMMT and the flame-inhibition effect of TAD were added in thermosets, but the OMMT/TAD system improved both the LOI and the UL 94 ratings of $4 \% \mathrm{TAD} / 1 \%$ OMMT/EP, OMMT and TAD should show additional flameretardant modes of action in TAD/OMMT/EP.

Thus the flame-retardant effects were evaluated quantitatively, by discussing the three main modes of action: flame inhibition, charring, and formation of a protective barrier layer. When $4 \%$ TAD and 1\% OMMT were incorporated into epoxy thermosets, the flame-retardant properties of $4 \% \mathrm{TAD} / 1 \%$ OMMT/EP obviously changed in comparison with $4 \% \mathrm{TAD} / \mathrm{EP}$, and the values of the three flame-retardant modes of action were calculated based on eqn (1)-(3). ${ }^{35}$ The results are listed in Table 5. First, 1\% OMMT/EP exhibited a negative influence on all three main flame-retardant effects.

$4 \%$ TAD greatly improved the flame-inhibition effect, because PO radicals released by TAD exerted a radicalquenching effect, but its barrier and thus protection effect was very poor. As for the $4 \% \mathrm{TAD} / 1 \% \mathrm{OMMT} / \mathrm{EP}$ sample, the protective-barrier effect obviously increased as compared with $1 \%$ OMMT/EP and $4 \% \mathrm{TAD} / \mathrm{EP}$. Usually, the barrier effect from flame retardants contribute to increasing flame retardancy of polymeric materials. Therefore, the increased flame retardancy of $4 \% \mathrm{TAD} / 1 \%$ OMMT benefited from the barrier effect of incombustible OMMT, although OMMT promoted burning at the early stage of combustion, shortening the TTI and time to 
Table 4 Cone calorimeter data of EP composites

\begin{tabular}{|c|c|c|c|c|c|c|c|c|}
\hline Samples & $\begin{array}{l}\text { PHRR } \\
\left(\mathrm{kW} \mathrm{m}^{-2}\right)\end{array}$ & $\begin{array}{l}\text { THR } \\
\left(\mathrm{MJ} \mathrm{m}^{-2}\right)\end{array}$ & $\begin{array}{l}\text { av-EHC } \\
\left(\mathrm{MJ} \mathrm{kg}^{-1}\right)\end{array}$ & $\begin{array}{l}\text { av-COY } \\
\left(\mathrm{kg} \mathrm{kg}^{-1}\right)\end{array}$ & $\begin{array}{l}\mathrm{av}-\mathrm{CO}_{2} \mathrm{Y} \\
\left(\mathrm{kg} \mathrm{kg}^{-1}\right)\end{array}$ & $\begin{array}{l}\text { TSR } \\
\left(\mathrm{m}^{2} \mathrm{~m}^{-2}\right)\end{array}$ & $\begin{array}{l}\text { TML } \\
\text { (wt\%) }\end{array}$ & $\begin{array}{l}\text { TTI } \\
(\mathrm{s})\end{array}$ \\
\hline $\mathrm{EP}(60-420 \mathrm{~s})$ & 1420 & 140 & 30.4 & 0.10 & 2.70 & 5885 & 90.3 & 56 \\
\hline 1\% OMMT/EP (45-240 s) & 1540 & 116 & 30.7 & 0.09 & 2.77 & 5975 & 90.6 & 39 \\
\hline $4 \% \mathrm{TAD} / \mathrm{EP}(60-275 \mathrm{~s})$ & 1106 & 82 & 23.3 & 0.13 & 2.40 & 4900 & 84.8 & 46 \\
\hline $4 \%$ TAD/1\% OMMT/EP (45-225 s) & 961 & 108 & 27.5 & 0.10 & 1.62 & 6991 & 83.6 & 41 \\
\hline Error scale & $\pm 3.2 \%$ & $\pm 1.7 \%$ & $\pm 2.8 \%$ & $\pm 2.0 \%$ & $\pm 2.4 \%$ & $\pm 3.9 \%$ & $\pm 1.2 \%$ & $\pm 0.2 \%$ \\
\hline
\end{tabular}

Table 5 Quantitative assessment of the three main flame-retardant modes of action

\begin{tabular}{|c|c|c|c|}
\hline Samples & Flame-inhibition effect & Charring effect & Barrier and protective effect \\
\hline 1\% OMMT/EP & $-1.3 \%$ & $-0.3 \%$ & $-30.4 \%$ \\
\hline $4 \% \mathrm{TAD} / \mathrm{EP}$ & $23.1 \%$ & $6.1 \%$ & $-33.2 \%$ \\
\hline $4 \% \mathrm{TAD} / 1 \% \mathrm{OMMT} / \mathrm{EP}$ & $9.2 \%$ & $7.4 \%$ & $12.2 \%$ \\
\hline
\end{tabular}

reach pk-HRR during combustion. Therefore OMMT is concluded to promote the decomposition of EP during burning and to cause earlier formation of inorganic-carbonaceous char. The earlier residue formation facilitated the protective effect on the matrix. The protective-barrier effect is the main flameretardant mode of action of OMMT in 4\% TAD/1\% OMMT/EP, accompanied by the flame-inhibition effect of TAD.

$$
\begin{gathered}
\text { Flame inhibition }=1-\text { EHCFREP/EHCEP } \\
\text { Charring }=1-\text { TMLFREP/TMLEP }
\end{gathered}
$$

Barrier and protective layer $=$

$$
1 \text { - (pk-HRRFREP/pk-HRREP)/(THRFREP/THREP) }
$$

\subsection{Macroscopic and microscopic morphologies of fire residues}

Fig. 6 shows the macroscopic digital photos of the residues of EP thermosets from cone calorimeter test, and Fig. 7 exhibits the SEM images of these microscopic residual char layers. As shown in Fig. 6a, the residual char of EP appeared very thin and broken, implying poor charring ability of EP itself. After OMMT was incorporated into EP, the char layer was thinner and even more fragmented, which proved that OMMT contributed to the combustion of EP. In Fig. 6c, the char yield of $4 \%$ TAD/EP was much greater than that of EP. It indicates that TAD promoted the formation of more char. These results were also confirmed in the cone calorimeter data. However, the char morphology in the middle part of the fire residue was loose and puffy, indicating the weak barrier and protection effect of $4 \%$ TAD/EP. Compared with $4 \%$ TAD/EP, the residual char of $4 \% \mathrm{TAD} / 1 \%$ OMMT/EP exhibited a more compact and tight morphology in Fig. 6d. The compact char layer protected the matrix from burning and obstructed heat release, thereby resulting in better flame retardancy of TAD/OMMT/EP. The results further supported the interpretation that OMMT's main mode of action is to increase the protective barrier effect of TAD/OMMT.
The microscopic morphologies of residues were further characterized via SEM, and the SEM images of $4 \%$ TAD/EP and 4\% TAD/1\% OMMT/EP in different magnification are shown in Fig. 7. As shown in Fig. 7a and b, there were a few open holes on the char surface of $4 \% \mathrm{TAD} / \mathrm{EP}$, and most of the char layer's surface exhibited a smooth, flat morphology. But because the char layer of $4 \% \mathrm{TAD} / \mathrm{EP}$ in macro morphology is loose and puffy, this kind of char layer cannot exert any barrier effect at all. As shown in Fig. 7c and d, the char layer surface of $4 \%$ TAD/ 1\% OMMT/EP was wrinkled and without open holes. After combustion, the organic compound of OMMT was decomposed, so there only left MMT in the char residue. It is worth noting that there were many small particles on the char layer surface, which suggests that MMT particles were embedded. This MMT incorporated in the residue generated by TAD/EP is
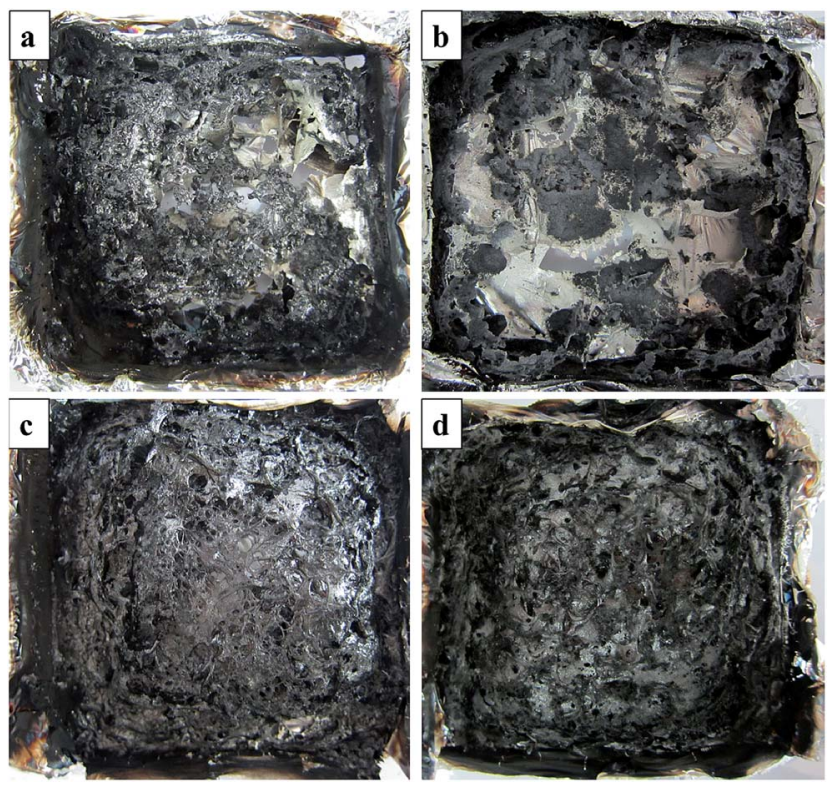

Fig. 6 Digital photo of residue from cone calorimeter tests: (a) EP; (b) 1\% OMMT/EP; (c) 4\% TAD/EP; (d) 4\% TAD/1\% OMMT/EP. 

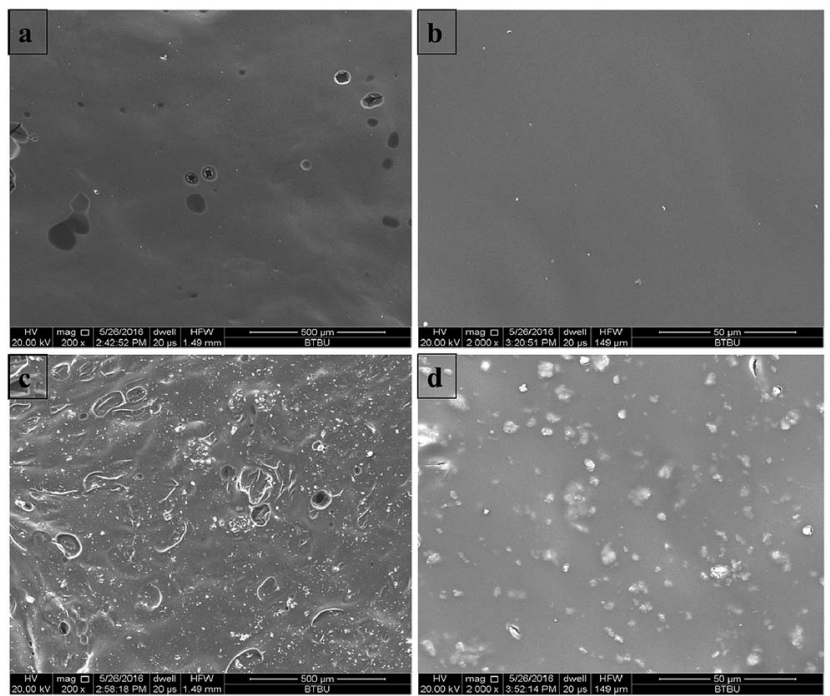

Fig. 7 SEM photo of residue from cone calorimeter tests: (a) 4\% TAD/ EP $\times 200$; (b) 4\% TAD/EP $\times 2000$; (c) 4\% TAD/1\% OMMT/EP $\times 200$; (d) $4 \% \mathrm{TAD} / 1 \%$ OMMT/EP $\times 2000$.

believed to further improve the protective-barrier effect of the carbonaceous char layer during flaming combustion..$^{31,37,38}$

\subsection{Elemental analysis of residues}

Additionally, the chemical contents of the residue from cone calorimeter and LOI tests were examined via XPS. The results of element contents are shown in Table 6 . In both the fire residue from LOI and that obtained in cone calorimeter tests, there were $\mathrm{Mg}, \mathrm{Al}$ and $\mathrm{Si}$ elements detected in the residues blended with MMT. This is evidence of MMT embedded in the surface of the char layer. The phosphorus content in residues from samples with TAD/OMMT is lower than that from samples without OMMT, indicating that OMMT may enhance the release of phosphorus from TAD. However, all phosphorus contents measured were very small, supporting the release of most of the phosphorus into the flame, forming PO radicals to exert the quenching effect in the gas phase.

\subsection{Flame-retardant mechanism}

In order to provide evidence for this deduction, the microscopic SEM pictures of the fire residues after early combustion were examined. In Fig. 8, particularly the fire residue edge of $4 \%$ TAD/1\% OMMT/EP exhibits the concentrated MMT particles. The MMT plates were oriented parallel to the surface, even
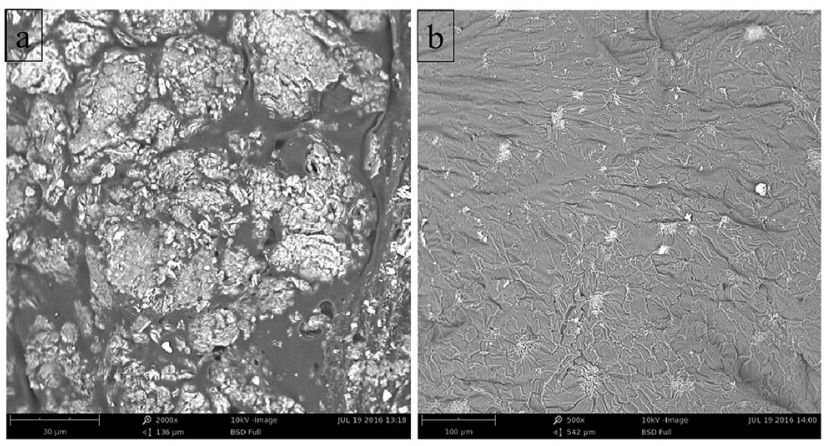

Fig. 8 (a) The SEM image of 4\% TAD/1\% OMMT/EP char formed under fire for $10 \mathrm{~s}(\times 2000$, the side part); (b) the SEM image of $4 \% \mathrm{TAD} / 1 \%$ OMMT/EP char formed under fire for $10 \mathrm{~s}(\times 500$, the middle part).

exhibiting dispersion, and thus seem to have spread somehow to cover the surface. The increased flame retardancy from OMMT in the $4 \% \mathrm{TAD} / 1 \% \mathrm{MMT} / \mathrm{EP}$ sample was caused by the barrier effect, particularly at the residue edges, through the agglomerated MMT plates formed during combustion. Although OMMT promoted burning at the beginning of combustion, the subsequent fire residue obtained is proposed to deliver the effective barrier effect from the concentrated OMMT at the side of the fire residue. The fire residue in the middle of the surface showed a less pronounced concentration

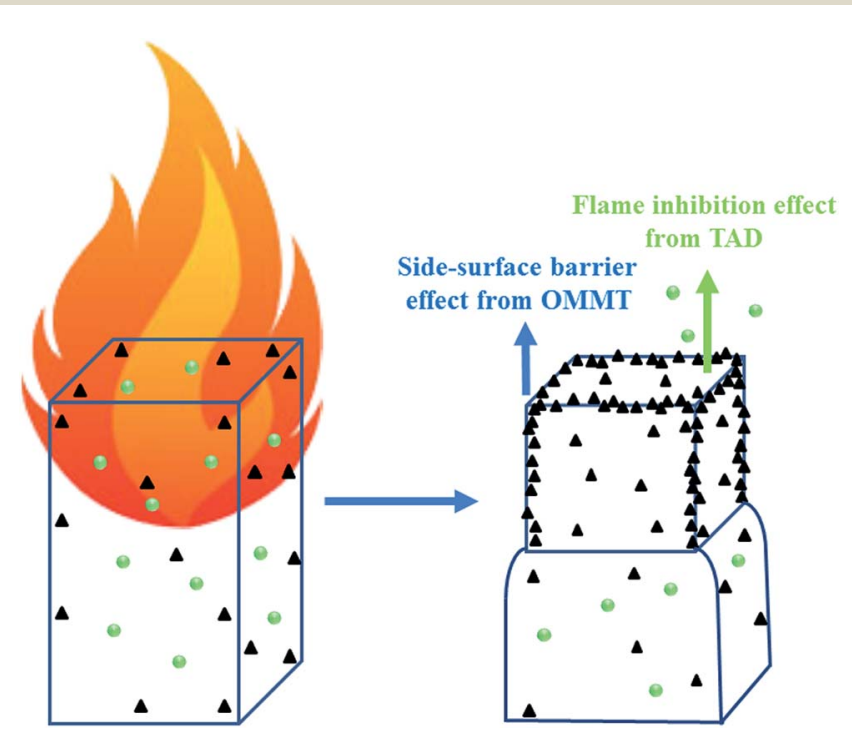

Fig. 9 Flame-retardant mechanism of OMMT in $4 \%$ TAD/ $1 \%$ OMMT/EP.

Table 6 Chemical contents of residues from cone calorimeter tests by XPS

\begin{tabular}{lllllll}
\hline Chemical contents & $\mathrm{C}(\%)$ & $\mathrm{N}(\%)$ & $\mathrm{O}(\%)$ & $\mathrm{P}(\%)$ & $\mathrm{Mg}(\%)$ & $\mathrm{Al}(\%)$ \\
\hline 4\% TAD/EP-LOI & 85.70 & 2.81 & 10.97 & 0.52 & - & - \\
$4 \%$ TAD/1\% OMMT/EP-LOI & 83.32 & 2.74 & 11.38 & 0.29 & 0.23 & 0.75 \\
$4 \%$ TAD/EP-CONE & 84.38 & 3.55 & 11.38 & 0.70 & - & - \\
$4 \%$ TAD/1\% OMMT/EP-CONE & 81.26 & 2.93 & 13.23 & 0.35 & 0.69 & 0.52
\end{tabular}


of OMMT, and thus would not provide the same outstanding protective effect. The specimen side-surface played a major role for performance in LOI and UL 94; thus, flame retardancy by the concentrated MMT promoted self-extinguishment in these tests. Because of the barrier protective effect particularly at the fire residue edges and the flame inhibition effect by TAD in the gas phase, OMMT and TAD worked together to achieve superior flame retardancy in $4 \% \mathrm{TAD} / 1 \% \mathrm{OMMT} / \mathrm{EP}$.

The flame-retardant mechanism of the OMMT/TAD system on epoxy thermosets is illustrated in Fig. 9. The initial flamepromotion effect contributed to the early formation of residue with concentrated pieces of MMT and produced a barrier effect at the side-surface of residue. TAD released the decomposed products with quenching effect from the phosphenanthrene group and those with dilution effect from the triazine-trione group, all of which have excellent flame-inhibition and fueldilution effects in the gas phase. When OMMT and TAD acted jointly to flame-retard epoxy thermosets, the better flame retardancy was generated by means of the barrier effect from MMT in the condensed phase and the flame inhibition effect from $\mathrm{TAD}$ in the gas phase.

\section{Conclusion}

In this thesis, OMMT, an efficient adjuvant, was incorporated into flame retardant TAD/EP. In 1\% OMMT/4\% TAD/EP, OMMT increased the LOI value to $36.9 \%$ and raised the UL 94 rating to $\mathrm{V}-0$. Although OMMT did not promote charring of the residue, the concentrated MMT, particularly at the fire residue sidesurface, became a protective barrier and promoted early selfextinguishment in flammability tests such as LOI and UL 94. The flame-retardant mode of action of OMMT is physical and occurred on a macroscopic scale. When OMMT and TAD were incorporated into epoxy thermosets together, OMMT exerted a protective-barrier effect in the condensed phase, working along with the flame-inhibition effect from TAD in the gas phase, resulting in the better flame-retardant performance of $4 \% \mathrm{TAD} / 1 \%$ OMMT/EP. The performance of the OMMT/TAD system is better than that of samples with TAD or OMMT alone.

\section{Acknowledgements}

Financial support was provided by the National Natural Science Foundation of China (No. 21374003) and the key project of the science and technology plan of the Beijing Municipal Education Commission \& the Beijing Natural Science Foundation (No. KZ201510011009).

\section{References}

1 B. Perret, B. Schartel, K. Stöß, M. Ciesielski, J. Diederichs, M. Döring, J. Krämer and V. Altstädt, Macromol. Mater. Eng., 2011, 296, 14-30.

2 R. C. Zhuang, J. Yang, D. Y. Wang and Y. X. Huang, RSC Adv., 2015, 5, 100049-100053.
3 K. Y. Li, C. F. Kuan, H. C. Kuan, C. H. Chen, M. Y. Shen, J. M. Yan and C. L. Chiang, Mater. Chem. Phys., 2014, 146, 354-362.

4 M. Dogan and S. Murat Unlu, Polym. Degrad. Stab., 2014, 99, 12-17.

5 D. Yu, M. Kleemeier, G. M. Wu, B. Schartel, W. Q. Liu and A. Hartwig, Polymer, 2011, 52, 2120-2131.

6 Z. H. Wang, P. Wei, Y. Qian and J. P. Liu, Composites, Part B, 2014, 60, 341-349.

7 Y. G. Zhang, X. Y. Pan, Y. F. Sun, W. Xu, Y. Q. Pan, H. F. Xie and R. S. Cheng, Construct. Build. Mater., 2014, 68, 62-67.

8 S. Yang, J. Wang, S. Q. Huo, M. Wang and J. P. Wang, Polym. Degrad. Stab., 2015, 121, 398-406.

9 L. J. Qian, Y. Qiu, J. Y. Wang and W. Xi, Polymer, 2015, 68, 262-269.

10 B. Schartel, A. I. Balabanovich, U. Braun, U. Knoll, J. Artner, M. Ciesielski, M. Döring, R. Perez, J. K. W. Sandler, V. Altstädt, T. Hoffmann and D. Pospiech, J. Appl. Polym. Sci., 2007, 104, 2260-2269.

11 B. W. Liu, H. B. Zhao, Y. Tan, L. Chen and Y. Z. Wang, Polym. Degrad. Stab., 2015, 122, 66-76.

12 C. Katsoulis, B. K. Kandola, P. Myler and E. Kandare, Composites, Part A, 2012, 43, 1389-1399.

13 M. El Gouri, A. El Bachiri, S. E. Hegazi, M. Rafik and A. El Harfi, Polym. Degrad. Stab., 2009, 94, 2101-2106.

14 P. Müller, M. Morys, A. Sut, C. Jäger, B. Illerhaus and B. Schartel, Polym. Degrad. Stab., 2016, 130, 307-319.

15 Y. Qiu, L. J. Qian and W. Xi, RSC Adv., 2016, 6, 56018-56027. 16 B. Perret, B. Schartel, K. Stöß, M. Ciesielski, J. Diederichs, M. Döring, J. Krämer and V. Altstädt, Eur. Polym. J., 2011, 47, 1081-1089.

17 L. P. Gao, D. Y. Wang, Y. Z. Wang, J. S. Wang and B. Yang, Polym. Degrad. Stab., 2008, 93, 1308-1315.

18 L. J. Qian, L. J. Ye, Y. Qiu and S. R. Qu, Polymer, 2011, 52, 5486-5493.

19 S. Yang, J. Wang, S. Q. Huo, J. P. Wang and Y. S. Tang, Polym. Degrad. Stab., 2016, 126, 9-16.

20 L. P. Gao, D. Y. Wang, Y. Z. Wang, J. S. Wang and B. Yang, Polym. Degrad. Stab., 2008, 93, 1308-1315.

21 B. Schartel, B. Perret, B. Dittrich, M. Ciesielski, J. Krämer, P. Müller, V. Altstädt, L. Zang and M. Döring, Macromol. Mater. Eng., 2016, 301, 9-35.

22 L. Zang, S. Wagner, M. Ciesielski, P. Müller and M. Döring, Polym. Adv. Technol., 2011, 22, 1182-1191.

23 X. Wang, L. Song, W. Y. Xing, H. D. Lu and Y. Hu, Mater. Chem. Phys., 2011, 125, 536-541.

24 X. Wang, Y. Hu, L. Song, H. Y. Yang, W. Y. Xing and H. D. Lu, Prog. Org. Coat., 2011, 71, 72-82.

25 W. C. Zhang, X. M. Li and R. J. Yang, Polym. Degrad. Stab., 2012, 97, 1314-1324.

26 T. Kawahara, A. Yuuki, K. Hashimoto, K. Fujiki, T. Yamauch and N. Tsubokawa, React. Funct. Polym., 2013, 73, 613-618.

27 P. P. Li, Y. P. Zheng, M. Z. Li, W. D. Fan, T. Shi, Y. D. Wang, A. B. Zhang and J. S. Wang, Composites, Part A, 2016, 81, 172181.

28 A. Laachachi, N. Burger, K. Apaydin, R. Sonnier and M. Ferriol, Polym. Degrad. Stab., 2015, 117, 22-29. 
29 M. Hesami, R. Bagheri and M. Masoomi, Iran. Polym. J., 2014, 23, 469-476.

30 A. Dasari, Z. Z. Yu, Y. W. Mai, G. P. Cai and H. H. Song, Polymer, 2009, 50, 1577-1587.

31 X. L. Chen, L. Liu, J. L. Zhuo, C. M. Jiao and Y. Qian, High Perform. Polym., 2015, 27, 233-246.

32 J. S. Im, S. K. Lee, S. J. In and Y. S. Lee, J. Anal. Appl. Pyrolysis, 2010, 89, 225-232.

33 B. Schartel, U. Knoll, A. Hartwig and D. Pütz, Polym. Adv. Technol., 2006, 17, 281-293.
34 S. Tang, L. J. Qian, X. X. Liu and Y. P. Dong, Polym. Degrad. Stab., 2016, 133, 350-357.

35 S. Brehme, T. Köppl, B. Schartel and V. Altstädt, e-Polym., 2014, 14, 193-208.

36 E. Wawrzyn, B. Schartel, H. Seefeldt, A. Karrasch and C. Jäger, Ind. Eng. Chem. Res., 2012, 51, 1244-1255.

37 B. Schartel, A. Weiß, H. Sturm, M. Kleemeier, A. Hartwig, C. Vogt and R. X. Fischer, Polym. Adv. Technol., 2011, 22, 1581-1592.

38 G. M. Wu, B. Schartel, H. Bahr, M. Kleemeier, D. Yu and A. Hartwig, Combust. Flame, 2012, 159, 3616-3623. 